\title{
Pre-School and Maternal Labour Outcomes: Evidence from a Regression Discontinuity Design
}

\section{IFS Working Paper W09/05}

Samuel Berlinski

Sebastian Galiani 
Preschool and Maternal Labor Market Outcomes:

Evidence from a Regression Discontinuity Design*

\author{
Samuel Berlinski \\ University College London and Institute for Fiscal Studies
}

Sebastian Galiani

Washington University in St. Louis

Patrick J. McEwan

Wellesley College

November 2008

\footnotetext{
${ }^{*}$ We thank Joseph Shapiro for his contributions to the paper. We further thank Phil Levine, Costas Meghir, Stephen Nickell, Imran Rasul, and the referees and editors for their useful suggestions. Samuel Berlinski gratefully acknowledges financial help from the ESRC-DFID grant RES-167-25-0124.
} 


\begin{abstract}
In developing countries, employment rates of mothers with young children are relatively lower. This paper analyzes how maternal labor market outcomes in Argentina are affected by the preschool attendance of their children. Using pooled household surveys, we show that four yearolds with birthdays on June 30 have sharply higher probabilities of preschool attendance than children born on July 1, given enrollment-age rules. Regression-discontinuity estimates using this variation suggest that preschool attendance of the youngest child in the household increases the probability of full-time employment and weekly hours of maternal employment. We find no effect of preschool attendance on maternal labor outcomes for children that are not the youngest in the household.
\end{abstract}

JEL Codes: I21, I28, J22

Keywords: female labor supply, Argentina, regression-discontinuity, kindergarten. 


\section{Introduction}

After World War II, female labor participation rates rose steadily in the developed and developing world. However, participation rates in many countries are still relatively low for mothers with young children. Not surprisingly, expanding preschool education is an oft-cited goal in both developed countries (OECD 2002) and Latin America (Myers 1995; Schady 2006). It provides an implicit child care subsidy, while also, perhaps, improving child outcomes (Blau and Currie 2006). While a subsidy specifically designed to achieve one of these goals will usually be relatively ineffective at accomplishing the other goal, the hope is that free public preschool could attain both. Nonetheless, the empirical evidence on the effects of pre-primary education is still limited, especially for developing countries. ${ }^{1}$

In two pertinent examples from South America, Berlinski, Galiani, and Gertler (forthcoming) find a positive effect of pre-primary school attendance on the Spanish and Mathematics test scores of Argentine third-graders, as well as behavioral outcomes such as attention, effort, class participation, and discipline. Berlinski, Galiani, and Manacorda (2008), using data from the Uruguayan household survey that collects retrospective information on preschool attendance, find small gains in school attainment from preschool attendance at early ages that are magnified with age. Less is known, however, about the effects of preschool on maternal labor market outcomes.

A major challenge in identifying the causal effect of pre-primary school attendance on child or parental outcomes is non-random selection into early education. To address this problem, our

\footnotetext{
${ }^{1}$ There is substantial empirical evidence from the United States that intensive early education interventions targeted specifically to disadvantaged children yield benefits in the short and in the long run (Blau and Currie 2006). On the less extensive evidence in Latin America, see Schady (2006).
} 
paper uses the fact that Argentine children must reach a given age prior to a preschool enrollment cutoff date. The school year runs from March to December, and enrollment in the final year of preschool is mandatory for children that turn five years old by June 30. Children born on July 1 must wait one year to enroll in kindergarten. Using pooled household surveys that report exact birth dates, we confirm that children born on July 1 have sharply lower probabilities, by about 0.3 , of attending school. We exploit this discontinuity in the probability of attendance to identify the effect of early school attendance on maternal labor market outcomes.

The parameters we study, however, differ from those of much research in the childcare and female labor supply literature. Though many studies have estimated the sensitivity of maternal employment to child care costs, their elasticity estimates cannot be easily generalized to predict the effects of expanding preschool education on maternal labor market outcomes (Anderson and Levine 2000; Blau and Currie 2006). ${ }^{2}$ Additionally, in the absence of credible instruments, identification of the elasticities of maternal employment to childcare costs is challenging (Browning 1992).

Our regression-discontinuity estimates suggest that, on average, 13 mothers start to work for every 100 youngest children in the household that start preschool (though, in our preferred specification, this estimate is not statistically significant at conventional levels). Furthermore, mothers are 19.1 percentage points more likely to work for more than 20 hours a week (i.e., more time than their children spend in school) and to work, on average, 7.8 more hours per week as a consequence of their youngest offspring attending preschool. We find no effect of preschool

\footnotetext{
${ }^{2}$ For the mothers that would work fewer hours than the school day, public schools provide a 100 percent marginal price subsidy for childcare of fixed quality, while for the mothers that would otherwise work more hours the price subsidy is inframarginal (Gelbach 2002).
} 
attendance on maternal labor outcomes for children that are not the youngest in the household. Finally, we find that at the point of transition from kindergarten to primary school there are persistent employment effects, even though school attendance by then is nearly universal. This might be explained by the fact that finding jobs takes time or by a mother's decision to work once the youngest child transitions to primary school.

Our preferred estimates condition on mother's schooling and other exogenous covariates, given evidence that mothers' schooling is unbalanced in the vicinity of the July 1 cutoff in the sample of four year-olds. Using a large set of natality records, we find no evidence that this is due to precise birth date manipulation by parents. Other explanations, like sample selection, are also not fully consistent with the data.

In terms of empirical strategies, Gelbach (2002) is the closest to the exercise we pursue in this paper. He uses U.S. census data to estimate the effect of public school enrollment of five year old children on their mothers' labor market outcomes, instrumenting enrollment with quarter of birth dummy variables. The idea is that the estimated parameters circumvent the problems of endogenity mentioned above while being informative about whether large subsidies in the form of limited, directly provided pre-primary education influence maternal labor outcomes. A related literature from several countries reports difference-in-differences estimates of preschool effects on maternal labor market outcomes, relying on geographic and temporal variation in policies that affect preschool attendance. ${ }^{3}$

\footnotetext{
${ }^{3}$ Cascio (forthcoming), exploits variation across the United States in the funding of kindergarten initiatives in the late 1960s and early 1970s. She finds positive effects of kindergarten enrollment on maternal labor supply for single mothers of five years-old with no younger children. Baker, Gruber and Milligan (2008) study the expansion of subsidized provision of childcare for children zero to four in the Canadian province of Quebec. They also find that childcare use has a positive effect on maternal labor supply for married mothers. Finally, Schlosser (2006) studies
} 
Of particular relevance to this paper's findings, Berlinski and Galiani (2007) examine an Argentine infrastructure program, initiated in 1993, that built pre-primary classrooms for children aged three to five. Using the fact that the construction exhibited variation in its intensity across provinces, difference-in-differences estimates suggest that the take-up of new preschool vacancies is perfect. The estimates further suggest that when a child is exogenously induced to attend preschool by the supply expansion, the likelihood of maternal employment increases between 7 and 14 percentage points, roughly similar to this paper's point estimates. However, Berlinski and Galiani only find a small, imprecisely estimated effect on hours worked.

The rest of the paper is organized as follows. Section II provides background information on the education system in Argentina and describes the datasets used in this paper. Section III describes our identification strategy. Section IV reports the empirical results, and section V concludes.

\section{Background and Data}

\section{A. Background Information}

Argentina is a middle-income developing country with a long tradition of free public schooling. The school system is divided into pre-primary, primary and secondary education. Primary school attendance between 6 and 12 years old is virtually universal. However, the preprimary attendance rate among children aged 3 to 5 years old is only 64\% in 2001 (Berlinski and Galiani 2007). Pre-primary education is divided into three levels: level 1 (age 3), level 2 (age 4),

the impact on labor supply of the gradual implementation of compulsory preschool laws for children aged three to four in Israel. She also finds that the provision of preschool education in Arab towns increases enrollment and maternal labor supply. 
and level 3 (age 5). In general, pre-primary classes are held within existing primary schools. Like primary schools, they typically operate in separate morning and afternoon shifts, with children attending one of these shifts for three and a half hours a day, five days a week, during a ninemonth school year.

Primary school has been compulsory since 1885. The Federal Education Law of 1993 further mandated attendance between level 3 of pre-primary education and the second year of secondary school. Its implementation was to have occurred gradually between 1995 and 1999, but it was not rigidly enforced. First, there is no penalty in place for non-compliers. Second, primary school enrollment is not impeded by lack of pre-primary schooling. Finally, there are still large dropout rates at ages 13 and older.

In Argentina, the academic school year starts early in March and finishes in December. Like many countries, a cutoff date establishes who can enroll in a given academic year. School age is defined by the age attained on June 30 of the current academic year. ${ }^{4}$ Children can enroll in level 3 of preschool if they turn five years old on or before June 30 of the current school year.

Until 1994 Argentina was a relatively low unemployment country with unemployment rates never exceeding 10 percent. However, unemployment increased substantially after a macroeconomic shock in 1995 with an average rate of 14.5 for the rest of the nineties. Annual hours worked are high and female participation is at the level of southern Europe. In 1998, the female employment rate for the group aged 18 to 49 was 48 percent.

The Argentine labor market is not very rigid. Tax rates in Argentina are comparable to those in a typical non-European OECD country. Unions are an important feature of economic life with around half the workers having their wages bargained collectively and 45 percent of employees

\footnotetext{
${ }^{4}$ See Art. 39, Resolución CABA: No 626/1980.
} 
being union members. However, national minimum wages are set at a relatively low level and probably do not have much impact on employment. Finally, employment protection is at about the average OECD level (Galiani and Nickell 1999).

\section{B. Data}

We use data from the Argentine household survey, the Encuesta Permanente de Hogares (EPH), a biannual survey of about 100,000 households managed by Argentina's National Institute of Statistics and Censuses (INDEC). The survey is representative of the urban population of Argentina. It has been conducted since 1974 in the main urban clusters (referred to as agglomerates) of each province of the country, with the exception of Rio Negro. ${ }^{5}$ A unique feature of this household survey is that from May 1995 to May 2003 it includes the exact date of birth for each individual in the sample. We pool repeated cross-sections of individual-level data from both waves of the survey covering the 1995 to 2001 period. We do not use the information for 2002 onwards because of the macroeconomic collapse of 2002 and its economic and distributional consequences (Galiani et al. 2003; Mussa 2002). ${ }^{6}$

For our main results, we use a sample of households including mothers between the ages of 18 and 49 and at least one child aged 4 on January 1 of the survey year. The survey collects information on the family relationship between household members and the head of household. Our analysis focuses on children of either male or female household heads, because only in such households can the mother of a child be identified in the EPH. We further restrict the sample to

\footnotetext{
${ }^{5}$ Urban Rio Negro was included in the survey in 2001. See, www.indec.gov.ar for detailed information on the EPH.

${ }^{6}$ GDP declined $20 \%$ and unemployment peaked at $24 \%$. The results using the 1995 to 2003 sample are similar to though less precise than those reported here and are available from the authors upon request.
} 
individuals with full information on date of birth, school attendance, mother's age and education, and siblings' ages. When children of the same household are born on the same day we only include one of the children in the household.

In the first panel of Table 1 we summarize the information contained in the EPH sample. On average, 58 percent of children aged 4 on January 1 of survey year attend school. However, the enrollment rate was 81 percent for those born in the first half of the year and 33 percent for those born on or after July 1 . Thirty-seven percent of the mothers worked the previous week, with 30 percent working 20 or more hours per week (i.e., more time than their children spend in school). The average number of hours worked last week is 12.17 . The employment rate for the mothers of children that attend preschool is 38 percent, versus 35 percent for those that do not. On average, maternal characteristics such as age, education and labor market outcomes for the mothers of children born in each half of the year are statistically similar.

We also use natality data from birth certificates, compiled by Argentina's Ministry of Health. ${ }^{7}$ It is not compulsory for provinces to report exact date of birth, but-with the exception of the Province of Buenos Aires-all other provinces provide this information for the period 2002-2005. ${ }^{8}$ From this data we extracted all births to mothers aged 14-45 (i.e., those who will be 18-49 when their children turns 4). In the second panel of Table 1 we summarize the information contained in the natality records.

\section{Empirical Strategy}

\footnotetext{
${ }^{7}$ Further information can be found at the Dirección de Estadísticas e Información de Salud website: http://www.deis.gov.ar/.

${ }^{8}$ Natality data before 2002 do not contain exact date of birth.
} 
This section describes the regression-discontinuity approach that we use to identify the effect of preschool attendance on maternal labor market outcomes. It exploits sharp differences in the probability of attendance for young children born on either June 30 or July 1 . As a starting point, consider the following linear model for a child aged 4 on January 1 of the survey year (i.e., a child who is going to turn 5 in the calendar and academic year of the survey):

$$
Y_{i j s}=\alpha S_{i j s}+\beta^{\prime} X_{i j s}+\lambda_{j}+\mu_{s}+\varepsilon_{i j s}
$$

where $Y_{i j s}$ is a labor market outcome for the mother of child $i$, residing in region $j$, and observed in survey round $s$ (each survey round is the interaction of year and wave of the survey). $S_{i j s}$ is a dummy variable indicating school attendance, $X_{i j s}$ is a vector of exogenous covariates that affect maternal labor market outcomes, and $\varepsilon_{i j s}$ is an error term assumed to be independent and identically distributed. The model includes fixed effects for regions $\left(\lambda_{j}\right)$, equivalent to survey "agglomerates", and survey rounds $\left(\mu_{s}\right)$. The parameter of interest, $\alpha$, represents the mean effect of a child's preschool attendance on the maternal labor market outcome. ${ }^{9}$ Because the effects of preschool attendance on maternal labor outcomes could differ between households whose youngest child enters kindergarten with respect to those who have younger children we estimate separate models and parameters for these groups.

If we estimate the model in equation (1) by Ordinary Least Squares (OLS), the estimator of $\alpha$ is likely to be inconsistent. First, maternal labor market outcomes and child's school attendance are jointly determined, introducing simultaneity bias. Second, omitted variables such as a

\footnotetext{
${ }^{9}$ In the case of dichotomous measures of labor market outcomes, we also apply OLS and interpret coefficient estimates as marginal probabilities.
} 
mother's cognitive ability are plausibly correlated with both labor outcomes and children's kindergarten attendance.

To disentangle the causal effect of preschool attendance, we use an instrument that induces plausibly exogenous variation in $S_{i j s}$, but has no direct effect on $Y_{i j s}$. In Argentina, children must turn 5 years old on or before June 30 of the school year in which they enroll in (compulsory) kindergarten. Those born one day later must wait a full year to enroll. Define a variable $B_{i j s}$ that indicates a child's day of birth during the calendar year. It equals -182 on January 1, 0 on July 1 , and 183 on December 31. Further define $Z_{i j s}=1\left\{B_{i j s} \geq 0\right\}$, an indicator function which equals to one for children born on or after July 1, and zero otherwise.

We model school attendance using a linear probability model:

$$
S_{i j s}=\delta_{0} Z_{i j s}+\delta_{1} B_{i j s}+\delta_{2} B_{i j s}^{2}+\delta_{3} Z_{i j s} \times B_{i j s}+\delta_{4} Z_{i j s} \times B_{i j s}^{2}+\lambda_{j}+\mu_{s}+v_{i j s}
$$

The parameter $\delta_{0}$ measures the discontinuity in preschool attendance on July 1 . In our sample of Argentine 4 year-olds, we anticipate that $\delta_{0}<0$, since children born on or after July 1 do not fulfill the minimum age requirement for enrollment in kindergarten. In practice, the point estimate is likely to be greater than -1 (a so-called "fuzzy" discontinuity), since younger children may already be enrolled in the previous, non-compulsory level of preschool, and some older children may ignore compulsory attendance rules.

Similarly, we can model maternal labor market outcomes as

$$
Y_{i j s}=\alpha_{0} Z_{i j s}+\alpha_{1} B_{i j s}+\alpha_{2} B_{i j s}^{2}+\alpha_{3} Z_{i j s} \times B_{i j s}+\alpha_{4} Z_{i j s} \times B_{i j s}^{2}+\lambda_{j}+\mu_{s}+\eta_{i j s}
$$

where $\alpha_{0}$ captures the reduced-form effect of July 1 birthdays on labor outcomes. Since we anticipate that $\delta_{0}>-1$, the estimate of $\alpha_{0}$ must be rescaled by the estimate of $\delta_{0}$ to recover the effect of school attendance on labor outcomes. In practical terms, this parameter is computed by 
estimating equation (1) via two-stage least squares (TSLS), conditioning on the interacted polynomials of $B_{i j s}$ and instrumenting $S_{i j s}$ with $Z_{i j s}$ (see, e.g., van der Klaauw 2002; Imbens and Lemiuex 2008).

For this to identify the parameter of interest, $Z_{i j s}$ must be correlated with $S_{i j s}$, but it should not have a direct effect on the outcome of interest, i.e. $\operatorname{cov}\left(Z_{i j s}, \varepsilon_{i j s}\right)=0$. Since parents can time conception, a child's season of birth is plausibly correlated with unobserved variables like child health and family income, any of which could directly influence maternal labor market outcomes (Bound, Jaeger, and Baker 1995; Bound and Jaeger 2000). To address this, the TSLS specifications control for smooth functions of $B_{i j s}$, estimated separately on either side of the cutoff date. ${ }^{10}$ The specification above assumes a piecewise quadratic polynomial, but we verify it through visual inspection of means taken within day-of-birth cells, in addition to obtaining estimates with higher-order polynomials.

Although the polynomials capture smooth, seasonal differences in birth date manipulation, they cannot capture precise manipulation, near the cutoff date, via cesarean sections or induced births. In the next section, we use natality data from birth certificates to show that this is an unlikely source of bias. Another possible threat to the internal validity of our estimates could come from welfare subsidies varying with school age. In this scenario, we could confound the effect of preschool attendance with the effect of these subsidies. To our knowledge, in Argentina, no such overlapping discontinuities exist in the design of the welfare system. Finally, parents

\footnotetext{
${ }^{10}$ The estimated regression functions do not fully saturate the model. Lee and Card (2008) show that one can interpret the deviation between the true conditional expectation function and the estimated regression function as random specification error that introduces a group structure into the standard errors for the estimated treatment effect. Thus, we always report standard errors clustered by 366 days of birth.
} 
may deceive educational authorities about their child's date of birth in order to enroll them in preschool earlier. This practice is difficult to implement in Argentina, since enrollment requires a national identification card that includes the officially-recorded date of birth. Moreover, this would only constitute a threat to internal validity if parents lie to the household survey about birth dates (in addition to the school authorities), which they have no incentive to do.

The interpretation of the TSLS estimates requires some clarification. ${ }^{11}$ Under a weak monotonicity assumption, as in Imbens and Angrist (1994), the estimates are informative about the behavior of compliers (i.e. the subgroup of individuals whose treatment status switches from nonrecipient to recipient if their birth date crosses the cut-off). ${ }^{12}$ Our analysis includes children that will turn 5 years old during the academic year. In this sample, the subgroup of noncompliers includes households that choose to send their children to preschool for two years or more, and thus are not influenced by the cutoff date. In contrast, the compliers include households that choose only one year of preschool. Thus, our estimates are most generalizable to households that choose less preschool, perhaps likely to be poorer and credit constrained, or with less access to preschool infrastructure.

\section{Main Results}

\footnotetext{
${ }^{11}$ One interpretation for the parameters we estimate is that of an equivalent cash childcare subsidy. We find this interpretation less straightforward as preschool education as a means of childcare imposes fixed costs on parents (e.g., children have to be taken and collected from school at certain times) that a childcare cash subsidy may not. Parents likely also value the learning of children during pre-primary education. Finally, the population that would be affected by these two conceptual experiments might be different.

${ }^{12}$ For a complete discussion of the fuzzy regression-discontinuity design, see Hahn, Todd, and van der Klaauw (2001) and Imbens and Lemieux (2008).
} 


\section{A. Evidence on Birth Timing}

We investigate the validity of our identifying assumption by examining whether there is manipulation of the assignment variable, perhaps via cesarean section or induced labor. ${ }^{13}$ It is plausible in Argentina, where one-quarter of births are via cesarean section, with rates between 36 and 45 percent in private hospitals (Belizán et al. 1999). Presuming that timed births do not occur from a random draw of the population, it is plausible that the clustering of such parents just to the left (or right) of the July 1 cutoff could introduce a correlation between $Z_{i j s}$ and $\varepsilon_{i j s}$.

We use two strategies to diagnose systematic manipulation of the assignment variable (Imbens and Lemieux 2008; Lee 2008). First, we examine the density of birthdates around the July 1 cutoff for clustering on either side of the cutoff. Second, we examine the distribution of observed socioeconomic and birth characteristics around the enrollment cutoff, interpreting sharp changes in these variables as suggestive of nonrandom birth date manipulation.

Figure 1 reports a histogram of births using large samples from the natality data. Black bars indicate the July 1 cutoff, as well non-floating holidays in Argentina, given evidence that birth frequencies are lower on such days. There is a strong case that families are capable of precisely timing births (McEwan and Shapiro 2008). The upper-left panel shows proportionally fewer births on weekends, and that mothers of such births have less schooling. This pattern, common across many countries, has been shown to be correlated with the use of cesarean sections and induced labor (Dickert-Conlin and Chandra 1999). To determine whether such birth timing

\footnotetext{
${ }^{13}$ In Chile, with a similarly high rate of cesarean sections (Belizán et al. 1999), McEwan and Shapiro (2008) found no evidence of birth timing around a July 1 enrollment cutoff. In the U.S., McCrary and Royer (2006) find no evidence of sorting around birthdate cutoffs in Texas and California. In other countries, evidence suggests that parents have manipulated birth dates in order to avoid taxes (Dickert-Conlin and Chandra 1999) and obtain monetary bonuses (Gans and Leigh Forthcoming).
} 
might occur around July 1, the upper-right panel reports a histogram of all births. Because of the large sample, we restrict it to a 6-month window around July 1, but the results are robust to a larger window. While there are visible dips in births on three national holidays, consistent with the ability to time births, there is no evidence of clustering of births on either side of July 1 .

In the bottom panels of Figure 1, we summarize the relationship between birth dates and two variables: weeks of gestation and mother's schooling. The circles represent the unadjusted means of these variables within daily cells. The superimposed lines are fitted values from a piecewise quadratic specification on date of birth. There is, interestingly, evidence that declines in birth frequencies on holidays are associated with lower values of mothers' schooling (indicated by the solid dots). However, there is no visual evidence of breaks around July 1.

In Table 2, we present OLS regression results that are the analogue of the visual evidence in the bottom panels of Figure 1. This table confirms the finding of no differences in gestation and schooling near the July 1 cutoff. It shows similar results for a larger set of covariates that include low birth weight. In sum, the natality data provide no evidence of systematic manipulation of birth dates around the July 1 cutoff.

\section{$\underline{\text { B. Day of Birth, Preschool Attendance, and Covariate Smoothness }}$}

We turn now to the analysis of preschool attendance and covariate smoothness using the EPH sample. In Figure 2, we summarize the relationship between birth date and preschool attendance. The top panels present results among 3 and 4 year-olds who are the youngest in the household, and the bottom panels among those that are not the youngest in the household. (In this and all subsequent analyses, children's age is calculated on January 1 of the survey year in which they 
are observed.) The circles represent unadjusted means of the school attendance variable within daily cells. The superimposed lines are fitted values from a piecewise quadratic specification.

Figure 2 shows, as expected, that preschool attendance is low among 3 year-olds. There is a small break in attendance, with children born on or just after July 1 slightly less likely to attend than children born just before. A larger break is evident among 4 year-olds, consistent with the fact that kindergarten (i.e., level 3 of preschool) is compulsory. Four year-olds born on July 1 are just below the minimum age requirement for kindergarten and must delay enrollment by one year, while 4 year-olds born on June 30 are eligible to enroll as the youngest kindergarteners.

Table 3 reports OLS estimates of equation (2), the empirical analogue of Figure 2. Panel A presents the results for the youngest children in the household, and Panel B the results for children who are not the youngest in the household. ${ }^{14}$ In column (1) of Panel A, where we only condition on a piecewise quadratic polynomial, we find that among 4 year-olds, the coefficient on birthdays after June 30 is a large, negative, and highly significant estimate of -0.31 . It is much smaller (-0.048) among 3 year-olds, albeit significant. In column (2), we add a full set of controls, including dummy variables for each survey round, regional agglomerate, day of week of birthday, birthdays on non-floating holidays, ${ }^{15}$ linear and quadratic terms of mother's age, a dummy variable indicating female children, and dummies for mother's years of schooling. The results are not statistically different than those reported in Column (1). The results for the sample

\footnotetext{
${ }^{14}$ A regression of a youngest in the household dummy on a born on/after July 1 dummy and a piecewise quadratic polynomial shows no correlation between being the youngest in the household and the July 1 dummy.

${ }^{15}$ We include these variables to show that the results are not driven by coincidental overlap of cutoff dates falling on weekends or holidays. Nevertheless, the results reported in the paper are very similar if we do not include these control variables.
} 
of children that are not the youngest in the households are similar, suggesting that this aspect of family structure does not affect compliance with the enrollment rule.

Before examining the effect of preschool attendance on maternal labor outcomes, we scrutinize whether, in the EPH sample, covariates are smooth around the cutoff point. In Table 4, we report successive OLS estimates of an equation like (3) for mother's age, years of schooling, and a dummy variable indicating whether the child is female. Panel A refers to the sample of children who are the youngest in the household, and Panel B to the sample of children who are not. The most obvious pattern is that mother's schooling is systematically lower among the youngest children in each household born on or after July 1 (that is, among children less likely to attend school). The basic result is robust to the inclusion of dummy variables for agglomerates, surveys, day-of-week of birth, and holiday births. Interestingly, mother's schooling is balanced around the cutoff for the sample of children that are not the youngest in the household and for those children aged 3. In Figure 3, we present the corresponding visual evidence for mother's schooling.

In Table 5, we present a number of robustness checks, both for the results on preschool attendance and mother's schooling. For brevity, we focus on the sample of 4 year-olds. We start by examining whether the quadratic specification is driving our results. Column (1) is the benchmark; for preschool attendance we reproduce the estimates of column (2) in Table 3, with the full set of controls, and for mother's schooling those of column (5) in Table $4 .{ }^{16}$ In columns (2) and (3), we respectively include cubic and quartic piecewise polynomials. In the remaining columns, we use a piecewise quadratic polynomial but within different samples. In column (4),

\footnotetext{
${ }^{16}$ The results for the mother's schooling equations are similar if we include other controls and use as the benchmark column (6) of Table 4.
} 
we focus on the sample of children born between April and September. In column (5), we drop a one week window at both sides of the cutoff. In column (6), we use survey weights. None of these changes in the specification of the analysis affects the basic results we have presented so far.

In the final two columns of Table 5, we present the results of a placebo experiment. In column (7), we take the sample of children born between January 1 and June 30. We center the date of birth variable on April 1 and we create a dummy for being born on or after April 1 that we interact with a quadratic polynomial. We report the coefficient of this dummy variable. In column (8), we conduct a similar exercise for those children born between July 1 and December 31. The dummy variable is now being born on or after October 1 . We find no statistically significant correlations between the outcomes and these dummy variables. However, it is worth noting that the coefficient on mother's years of schooling can be large (the p-value is 0.115 ) as the result in column (7) shows.

The fact that covariates are smooth around July 1 in the natality data reduces the plausibility of systematic manipulation of birth dates as an explanation for the robust correlations just observed. One alternative explanation is sample selection. This could happen, for example, if relatively less-educated mothers of children born before July 1 are induced to work more than the mothers of children born on or after July 1, and also are less likely to be interviewed by the household survey as a result. Though a potentially compelling explanation, the point estimates are large enough to render it less plausible. On average, the mothers of children age 4 completed 9.37 years of education with $64.4 \%$ of these mothers completing 9 or less years of education. ${ }^{17}$

\footnotetext{
${ }^{17}$ The distribution of years of education for the mothers of children age 4 is: $0(0.85 \%), 3(11.16 \%), 7(30.00 \%), 9$ (22.53\%), $12(16.74 \%), 14(2.29 \%), 15(11.46 \%)$ and $17(5.08 \%)$.
} 
Suppose that the mothers with less than the average level of education are selecting out of the sample at the same rate over the whole education distribution. In this case, we need approximately $38 \%$ of these mothers to disappear from the sample to generate a difference of 0.8 years of education. ${ }^{18}$

Furthermore, we find large differences in schooling among the mothers of the non-youngest children aged 1 and 2 years old (the results are not reported in the tables). Almost none of these children attend school, so it is unlikely to result from labor-supply induced sample selection. As it stands, the most likely explanation is noise, though we cannot rule out the presence of sample selection. As a result, our preferred estimates in the next section control for mothers' schooling. The unconditional instrumental variables estimates will likely be biased upwards because of the positive correlation between education and labor market outcomes. Of course, to the extent that selection on unobservables is plausible, our results might still be biased, although the direction of the bias is not clear.

\section{School Attendance and Maternal Labor Outcomes}

In Table 6, we report estimates from reduced-form regressions of mother's labor market outcomes on a dummy variable indicating births on or after July 1. The variables include whether mothers were employed last week, whether mothers worked for at least 20 hours last week ("fulltime"), and the number of hours worked last week. We estimate separate OLS regressions of equation (3) for children aged 3 and 4. All regressions control for a piecewise quadratic of birth

\footnotetext{
${ }^{18}$ The distribution of years of education if 38 percent of the mothers with less than 9.317 years of education drop out from the sample would be: 0 (0.70\%), 3 (9.08\%), 7 (24.63\%), 9 (18.50\%), 12 (22.17\%), 14 (3.03\%), 15 (15.18\%) and $17(6.73 \%)$. Therefore, average years of education is 10.166 .
} 
date, while regressions in even columns include a full set of controls. Because children born on or after July 1 are less likely to attend school, we expect a negative effect for maternal labor outcomes of being born on or after July 1.

In the samples of 3 year-olds, none of the coefficients are statistically distinguishable from zero. This is perhaps not surprising given the relatively small difference in school attendance around the July 1 cutoff for such children. For children aged 4 that are the youngest in the household, the coefficients in Table 6 range between -0.066 and -0.038 when a dichotomous indicator of mother's employment is the dependent variable. Coefficients range between -0.085 and -0.058 when the dependent variable is work for more than 20 hours a week. In columns (5) and (6), mothers of children born in the second semester of the year work between 2.4 and 3.4 less hours in the previous week. Not surprisingly, given the evidence from the previous section, the coefficients from fully-specified models are less negative. The pattern of the reduced-form results just described is corroborated in Figure 4, which presents unsmoothed means and fitted values for children aged 4, for the youngest children (upper panels) and not youngest (lower panels).

Despite the fact that there is a significant increase in preschool attendance among children aged 4 that are not the youngest in the household, there is no evidence of changes in employment or hours of work for their mothers. In theory, it is plausible that there could be an effect on these outcomes for the mothers of these children as the childcare provided by preschool attendance of at least one of their children contributes towards reducing the total cost of childcare. However, the result implies that this contribution is small relative to the cost of childcare for the other children and does not affect the decision of the mother to either work or work for more hours. 
Table 7 reports two-stages least squares estimates, which are simply the reduced-form estimates from Table 6 divided by the changes in the probability of attendance estimated among 4 year-olds in Table 3. Among the sub-sample of youngest children (panel A), the model with the full set of controls suggests that mothers with children attending kindergarten are 12.7 percentage points more likely to work, though the estimate is not precise. This means that 13 mothers start working for every 100 youngest children in the household that start preschool. Furthermore, mothers are 19.1 percentage points more likely to work more than 20 hours per week, and they work, on average, 7.8 more hours per week as consequence of their youngest child attending preschool. Both estimates are statistically significant at the 10 percent level. The point estimates of the binary employment measures are consistent with the upper end of estimates reported in Berlinski and Galiani (2007), who used a different EPH sample and an empirical strategy using temporal and regional variation in preschool construction.

In Table 8, we report a set of robustness checks for the two-stages least squares estimates. ${ }^{19}$ Column (1) is the benchmark, reproducing estimates from columns (2), (4) and (6) in Table 7. In columns (2) and (3), we use cubic and quartic polynomials respectively. In the remaining columns of Table 5, we use a piecewise quadratic polynomial but within different samples. In column (4), we focus on the sample of children born between April and September. In column (5), we drop a one-week window on each side of the cutoff. In column (6), we use survey

\footnotetext{
${ }^{19}$ We have also estimated the effect of preschool attendance on maternal labor outcomes using locally weighted regressions (results available upon request from the authors). The estimates for the youngest in the household are similar in magnitude to those presented in Table 7 and robust to the choice of bandwidth. However, they are imprecisely estimated. For children who are not the youngest in the household the magnitude of the estimates tend to be positive but are quite sensitive to the bandwidth choice and are also imprecisely estimated.
} 
weights. ${ }^{20}$ The results in Panel A are similarly-signed, but less precise than in the benchmark specification. The most noticeable difference is that when we weight observations using the survey weights, the results for the non-youngest children in the household (panel B) tend to be similar to the results for the youngest children.

\section{$\underline{\text { D. Heterogeneous Effects }}$}

We have shown that the effect of the enrollment rule on preschool attendance is not affected by whether there are younger siblings in the household. However, the maternal labor market response to the preschool enrollment rule for 4 year old children is remarkably different for the mothers of children with and without younger siblings. We next explore whether other variables that are likely to affect maternal home and market productivity, such as age and schooling, impact their behavioral responses to the enrollment rule.

In Table 9, we report estimates from OLS regressions of school attendance, mother's schooling, mother's employment, employment for more than 20 hours last week, and hours worked last week on a dummy variable indicating births on or after July 1 for four samples of 4 year old children: mothers aged 35 or older, mothers younger than 35 years of age, mothers with incomplete high school or lower educational achievement, and mothers with complete high school education or higher educational achievement. All regressions control for a piecewise quadratic of birth date, while regressions in even columns include a full set of controls. Panel A present results for children that are the youngest in the household and panel B for other children.

\footnotetext{
${ }^{20}$ Because in the placebo experiments from Table 5 the effect on attendance is close to zero, the corresponding twostage least squares estimates are close to zero as well.
} 
We find that effect of the enrollment rule on preschool attendance is not significantly different between children with mothers of different ages. There is some evidence that the preschool attendance of youngest children in the household with mothers that have lower education is more sensitive to the enrollment rule-about 6 percentage points-but this difference is not statistically significant. The lack of balancing on maternal education persists for the youngest children in the household regardless of their mothers' age group. Dividing the sample by maternal education seemingly resolves the lack of balancing in maternal education around the cutoff. However, this appears to be a mechanical consequence of censoring the dependent variable, and does not provide any goods news for identification.

In terms of labor market responses, the effects are still concentrated among mothers for whom the child is the youngest in the household. Despite the fact that the enrollment rule produces similar responses in term of preschool attendance for the different groups, we find that the effects on employment and hours of work are driven by older and less educated mothers. For example, among the sub-sample of youngest children (panel A), the model with the full set of controls suggests that mothers with children born on or after July 1 were 8.4 percentage points less likely to work, 11 percentage points less likely to work full time, and worked 5 hours less per week. This is equivalent to an effect of preschool attendance on employment of 19 percentage points, on full-time work of 23 percentage points, and on hours work of 11.65 hours. ${ }^{21}$ We speculate that older mothers with young children are either less likely to have additional children or have more attachment to the labor market, and thus are more responsive when their youngest child starts preschool. In the absence of a comprehensive welfare system, as

\footnotetext{
${ }^{21}$ Instrumental variables results available from the authors upon request.
} 
in Argentina, less-educated mothers may also have the need to return to work as soon as it is feasible.

\section{E. Day of Birth and Maternal Outcomes for Primary School Children}

In Table 10, we reproduce estimates for school attendance, mother's schooling, mother's employment, employment for more than 20 hours last week, and hours worked last week for children aged 5 and 6 on July 1 of the survey year. School enrollment is uniformly high at these ages and there is no enrollment effect of July 1 births. The correlation between maternal schooling and being born in the second semester still persists. We find that for children aged 5 that are the youngest in the household the maternal labor outcomes coefficients in Table 10 tend to be of similar sign and magnitude than those of the youngest children aged 4 we reported in Table 6. We find no systematic effects for children aged 6 or for those children that are not the youngest in the household.

Why do we observe employment effects for children aged 5 when there is no school attendance discontinuity? One explanation is that the result is an statistical artifact reflecting a lack of balancing in the observables. Although this is theoretically plausible, it does not explain why, in our sample, such a correlation does not exist at age 6 . An alternative explanation is that although some mothers find employment at the moment when their children start kindergarten, for others it takes time to find suitable employment so that some effects appear at age 5. Given the similarity in the magnitude of the coefficients between ages 4 and 5, one suspects that this cannot be the whole story. A complementary explanation is that, at age 5, the dummy for being born on or after July 1 picks up the difference between being enrolled in kindergarten and primary school. If the maturity of a child plays a role on the decision of a mother to go work, the 
transition from kindergarten to primary school may be interpreted by families as a signal that inhome care is no longer necessary. ${ }^{22}$ This is consistent with the fact that no such effect appears at age 6 .

\section{Conclusion}

Expanding preschool education has the dual goals of improving child outcomes and work incentives for mothers. This paper provides evidence on the second, identifying the impact of preschool attendance on maternal labor market outcomes in Argentina. A major challenge in identifying the causal effect of preschool attendance on parental outcomes is non-random selection into early education. We address this by relying on plausibly exogenous variation in preschool attendance that is induced when children are born on either side of Argentina's enrollment cutoff date of July 1. Because of enrollment cutoff dates, 4 year-olds born just before July 1 are 0.3 more likely to attend preschool. Our regression-discontinuity estimates compare maternal employment outcomes of 4 year-old children on either side of this cutoff, identifying effects among the subset of complying households (who are perhaps more likely to face constraints on their level 2 preschool attendance).

Our findings suggest that, on average, 13 mothers start to work for every 100 youngest children in the household that start preschool (though, in our preferred specification, this estimate is not statistically significant at conventional levels). Furthermore, mothers are 19.1 percentage points more likely to work for more than 20 hours a week (i.e., more time than their children spend in school) and they work, on average, 7.8 more hours per week as consequence of

\footnotetext{
${ }^{22}$ A more practical explanation is that primary schools may have longer school days and hence provide a larger implicit subsidy. Nevertheless, primary schools, like preschools, also operate mainly on a two-shift schedule.
} 
their youngest offspring attending preschool. We find no effect on maternal labor outcomes when a child that is not the youngest in the household attends preschool. Finally, we find that at the point of transition from kindergarten to primary school some employment effects persist.

Our preferred estimates condition on mother's schooling and other exogenous covariates, given evidence that mothers' schooling is unbalanced in the vicinity of the July 1 cutoff in the sample of 4 year-olds. Using a large set of natality records, we found no evidence that this is due to precise birth date manipulation by parents. Other explanations, like sample selection, are also not fully consistent with the data, and we must remain agnostic on this point. Despite this shortcoming, the credibility of the estimates is partly enhanced by the consistency of point estimates with Argentine research using a different EPH sample and sources of variation in preschool attendance (Berlinski and Galiani 2007).

A growing body of research suggests that pre-primary school can improve educational outcomes for children in the short and long run (Blau and Currie 2006; Schady 2006). This paper provides further evidence that, ceteris paribus, an expansion in preschool education may enhance the employment prospects of mothers of children in preschool age. ${ }^{23}$

\footnotetext{
${ }^{23}$ However, as a referee notes, the large-scale expansion of preschool might have additional effects not reflected in our empirical results. For example, one could imagine that it increases fertility, which could have countervailing effects on labor supply among women.
} 


\section{References}

Anderson, Patricia M., and Philip B. Levine. 2000. "Child Care and Mothers' Employment Decisions.” In Finding Jobs: Work and Welfare Reform, ed. David Card and Rebecca M. Blank. New York: Russell Sage Foundation.

Baker, Michael, Jonathan Gruber, and Kevin Milligan. 2008. "Universal Childcare, Maternal Labor Supply and Family Well-Being.” Journal of Political Economy 116: 709-45.

Belizán, José M., Fernando Althabe, Fernando C. Barros, and Sophie Alexander. 1999. "Rates and Implications of Caesarean Sections in Latin America: Ecological Study.” British Medical Journal 319: 1397-400.

Berlinski, Samuel, and Sebastian Galiani. 2007. "The Effect of a Large Expansion of PrePrimary School Facilities on Preschool Attendance and Maternal Employment.” Labour Economics 14: 665-80.

Berlinski, Samuel, Sebastian Galiani, and Paul Gertler. Forthcoming. "The Effect of Pre-Primary Education on Primary School Performance.” Journal of Public Economics.

Berlinski, Samuel, Sebastian Galiani, and Marco Manacorda. 2008. "Giving Children a Better Start: Preschool Attendance and School-Age Profiles." Journal of Public Economics 92: $1416-40$.

Blau, David, and Janet Currie. 2006. "Pre-School, Day Care, and After School Care: Who's Minding the Kids?" In Handbook of the Economics of Education (vol. 2), ed. Eric Hanushek and Finis Welch. Amsterdam: Elsevier.

Bound, John, and David A. Jaeger. 2000. "Do Compulsory Attendance Laws Alone Explain the Association Between Earnings and Quarter of Birth?" In Research in Labor Economics: Worker Well-Being, ed. Solomon W. Polacheck. New York: JAI. 
Bound, John, David A. Jaeger, and Regina M. Baker. 1995. "Problems with Instrumental Variables Estimation When the Correlation Between the Instruments and the Endogenous Explanatory Variable is Weak." Journal of the American Statistical Association 90: 443-50.

Browning, Martin. 1992. "Children and Household Economic Behavior.” Journal of Economic Literature 30: 1434-75.

Cascio, Elizabeth. Forthcoming. "Maternal Labor Supply and the Introduction of Kindergartens into American Public Schools.” Journal of Human Resources.

Dickert-Conlin, Stacy, and Amitabh Chandra. 1999. "Taxes and the Timing of Births." Journal of Political Economy 107: 161-77.

Galiani, Sebastian, Daniel Heymann, and Mariano Tommasi. 2003. "Great Expectations and Hard Times: The Argentina Convertibility Plan.” Economía 4: 109-60.

Galiani, Sebastian, and Stephen Nickell. 1999. "Unemployment in Argentina in the 1990s." Working Paper DTE 219, Instituto Torcuato Di Tella.

Gans, Joshua S., and Andrew Leigh. Forthcoming. "Born on the First of July: An (Un)natural Experiment in Birth Timing." Journal of Public Economics.

Gelbach, Jonah B. 2002. "Public Schooling for Young Children and Maternal Labor Supply." American Economic Review 92: 307-22.

Hahn, Jinyong, Petra Todd, and Wilbert van der Klaauw. 2001. "Identification and Estimation of Treatment Effects with a Regression-Discontinuity Design.” Econometrica 69: 201-9.

Imbens, Guido W., and Joshua D. Angrist. 1994. "Identification and Estimation of Local Average Treatment Effects.” Econometrica 62: 467-75.

Imbens, Guido W., and Thomas Lemieux. 2008. "Regression Discontinuity Designs: A Guide to Practice." Journal of Econometrics 142: 615-35. 
Lee, David S. 2008. "Randomized Experiments from Non-Random Selection in U.S. House Elections." Journal of Econometrics 142: 675-97.

Lee, David S., and David Card. 2008. "Regression Discontinuity Inference with Specification Error.” Journal of Econometrics 142: 655-74.

McCrary, Justin, and Heather Royer. 2006. "The Effect of Maternal Education on Fertility and Infant Health: Evidence from School Entry Laws Using Exact Date of Birth.” Unpublished manuscript, University of Michigan and Case Western.

McEwan, Patrick J., and Joseph S. Shapiro. 2008. "The Benefits of Delayed Primary School Enrollment: Discontinuity Estimates Using Exact Birth Dates." Journal of Human Resources 43: 1-29.

Mussa, Michael. 2002. Argentina and the Fund. From Triumph to Tragedy. Washington, DC: Petersen Institute.

Myers, Robert J. 1995. "Preschool Education in Latin America: Estate [sic] of practice." Working Paper No. 1, PREAL, Washington, DC.

OECD. 2002. "Strengthening Early Childhood Programs: A Policy Framework." In Education Policy Analysis, Paris.

Schady, Norbert. 2006. "Early Childhood Development in Latin America and the Caribbean." Economía 6: 185-225.

Schlosser, Analía. 2006. "Public Preschool and the Labor Supply of Arab Mothers: Evidence from a Natural Experiment.” Unpublished manuscript, Hebrew University of Jerusalem. van der Klaauw, Wilbert. 2002. "Estimating the Effect of Financial Aid Offers on College Enrollment: A Regression-Discontinuity Approach.” International Economic Review 43: 1249-87. 


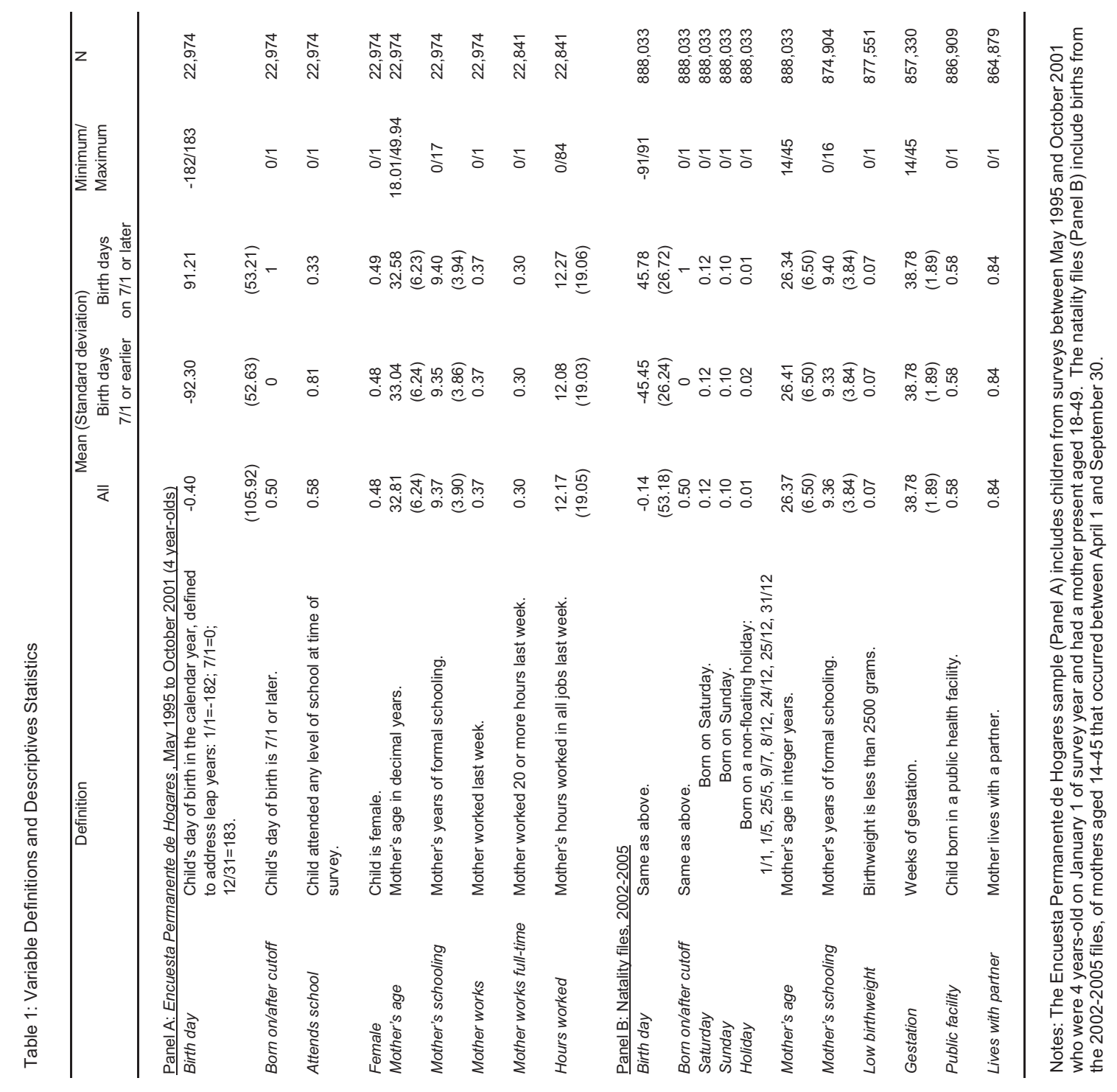




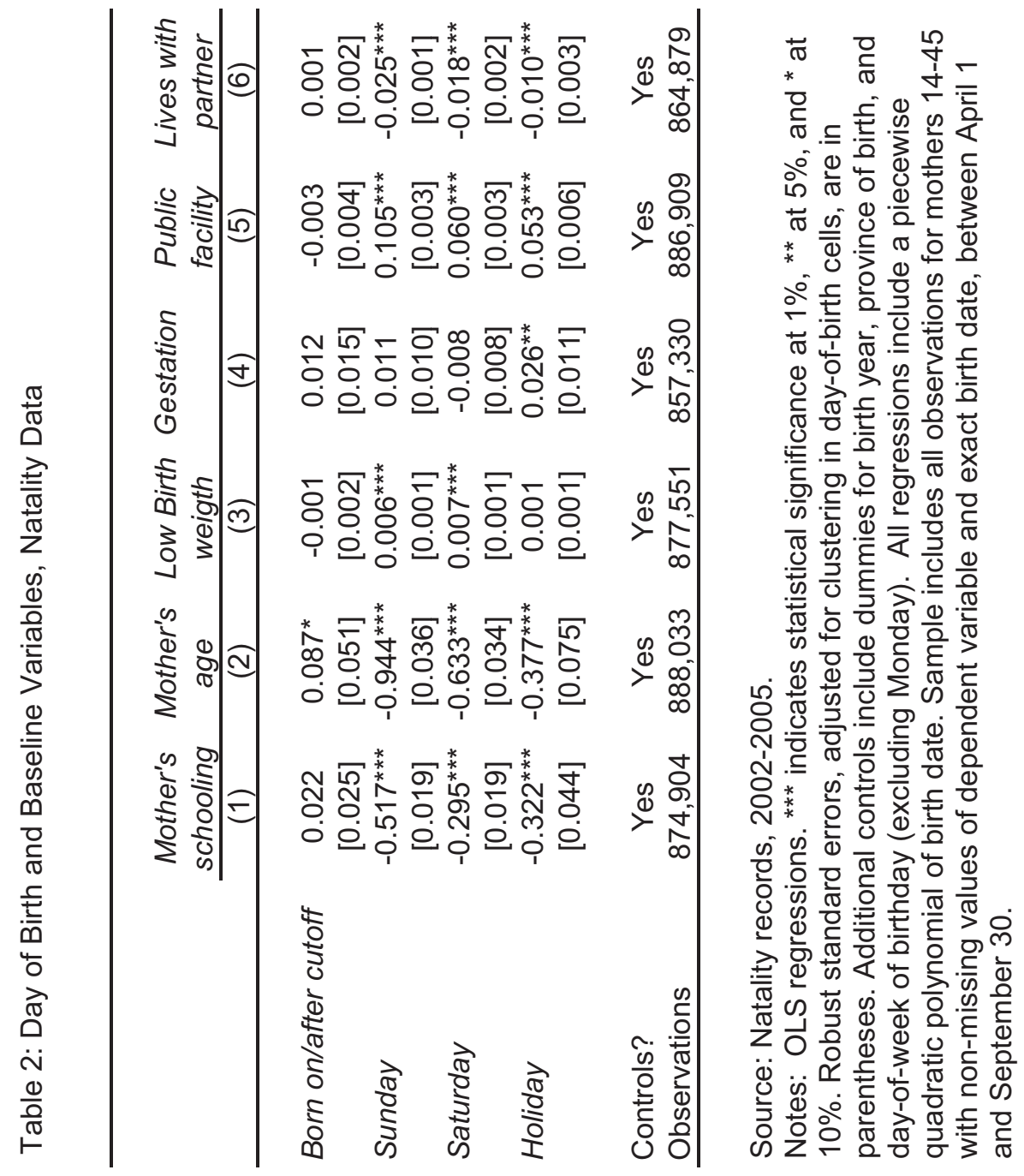




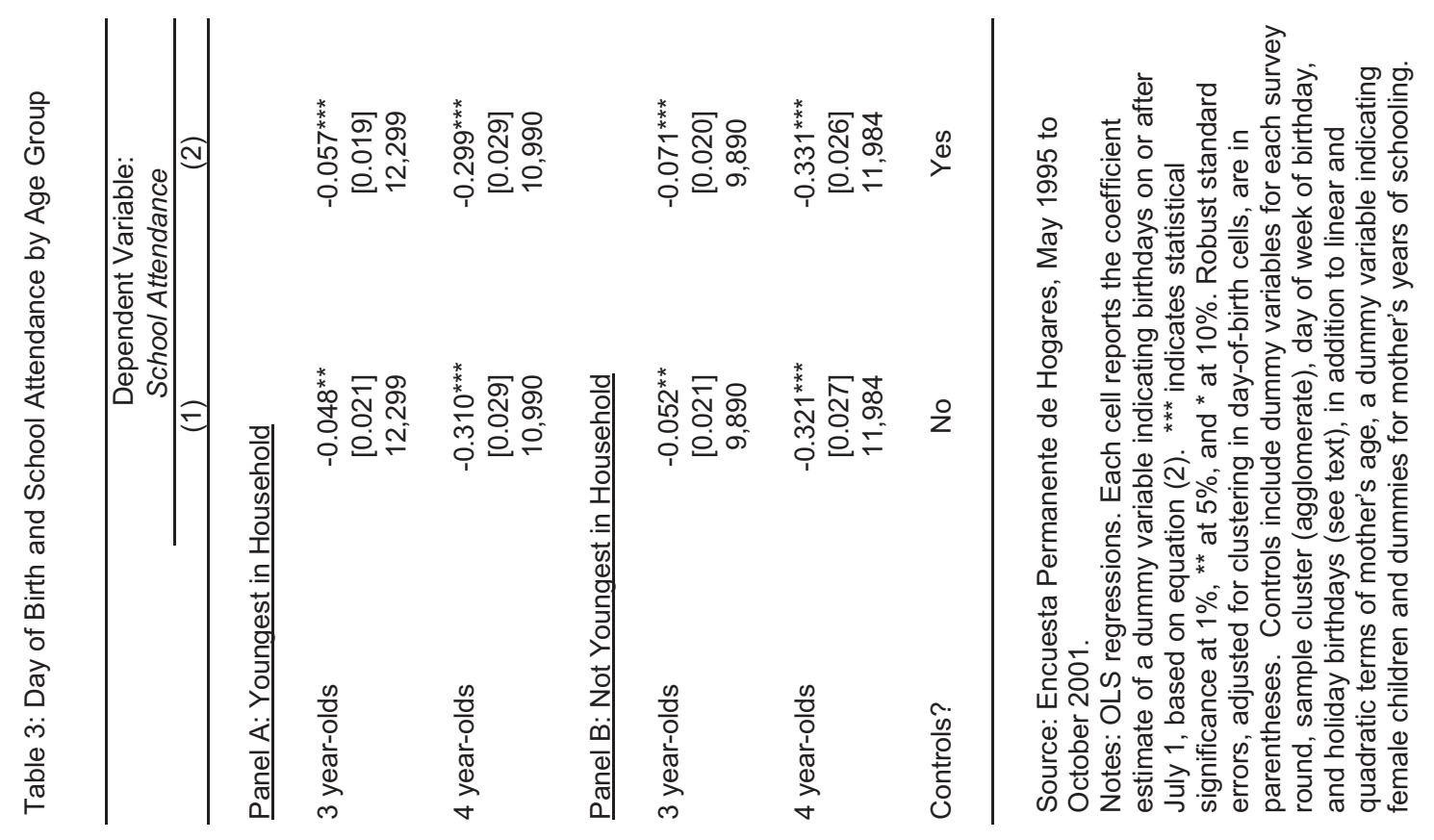




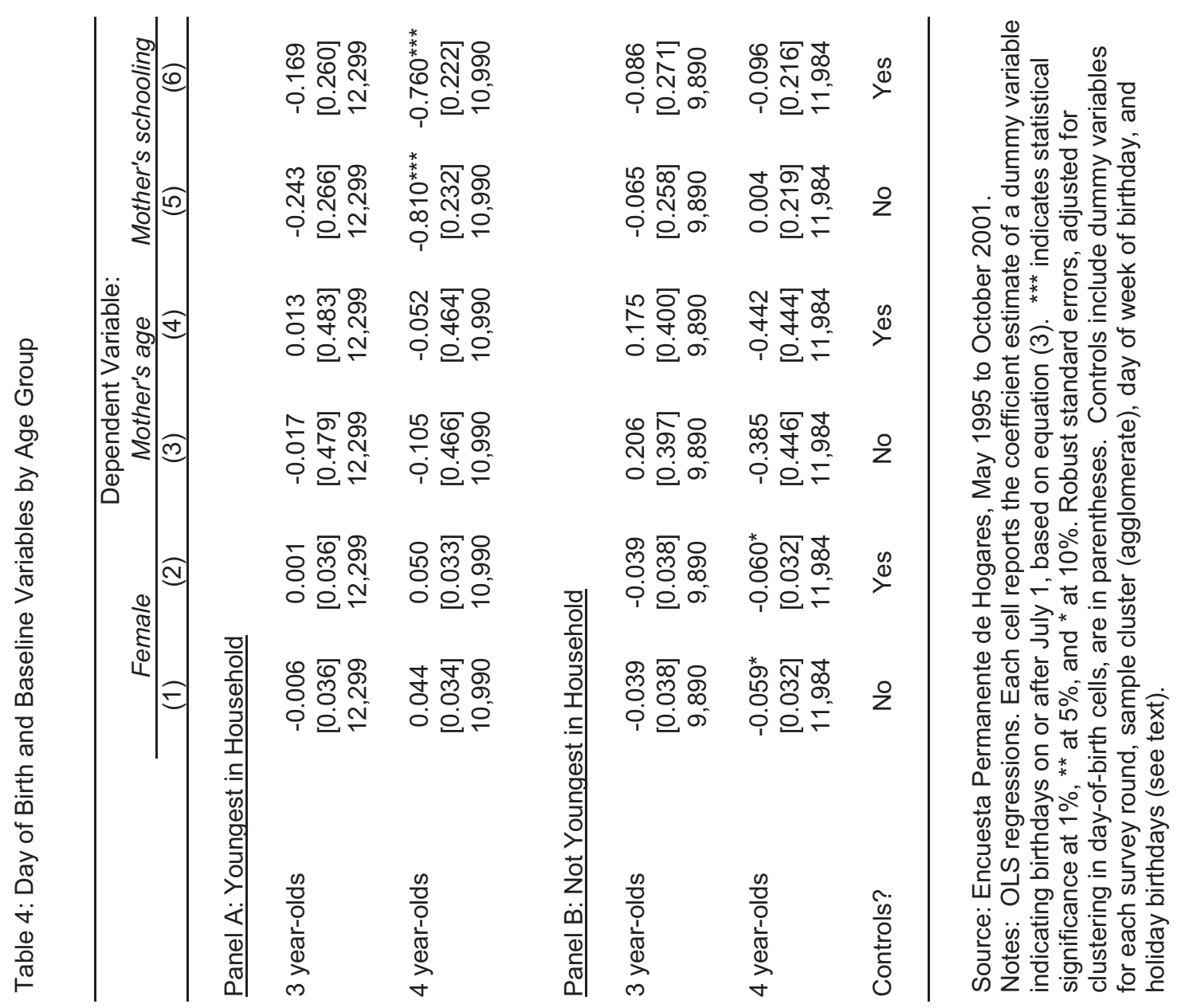




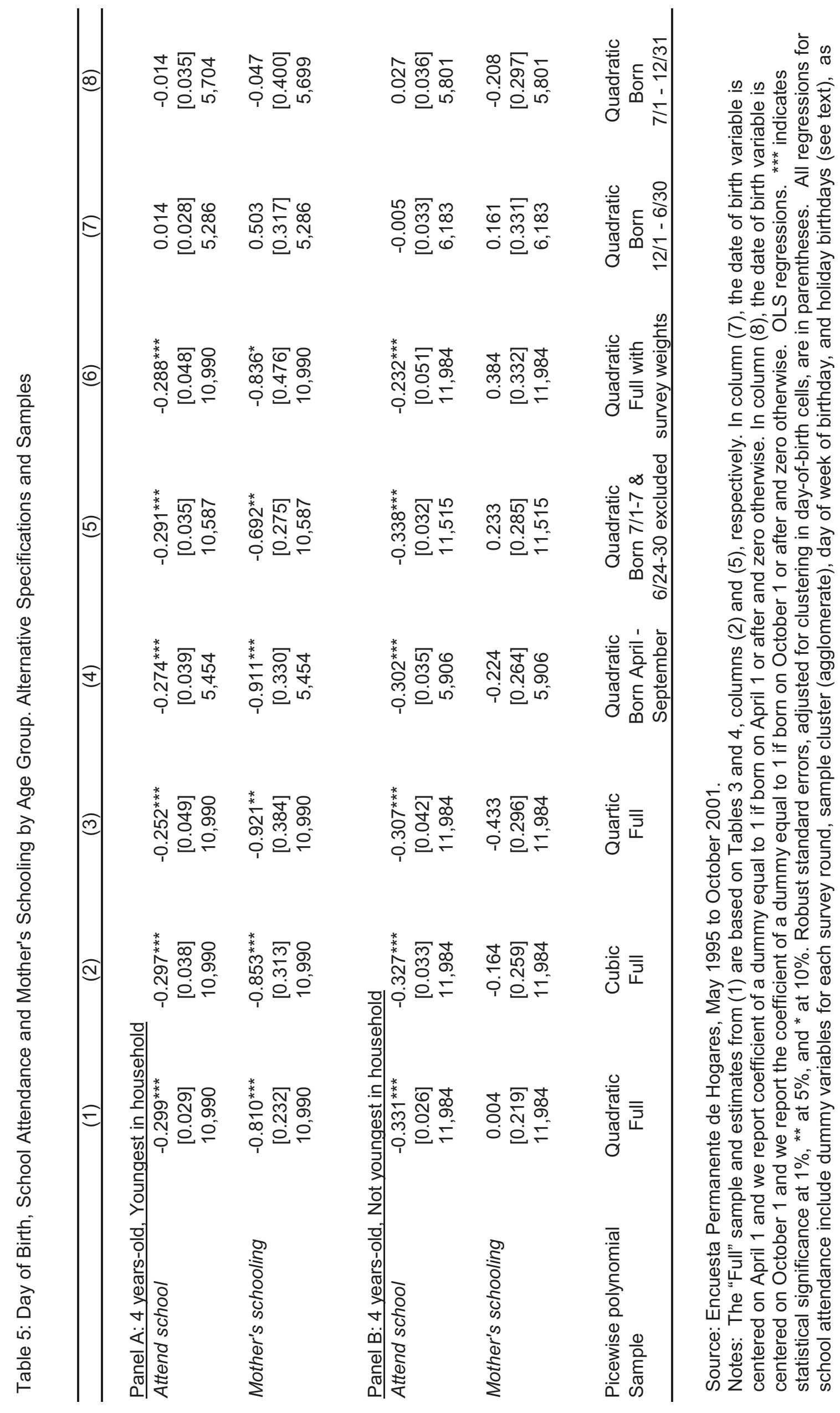




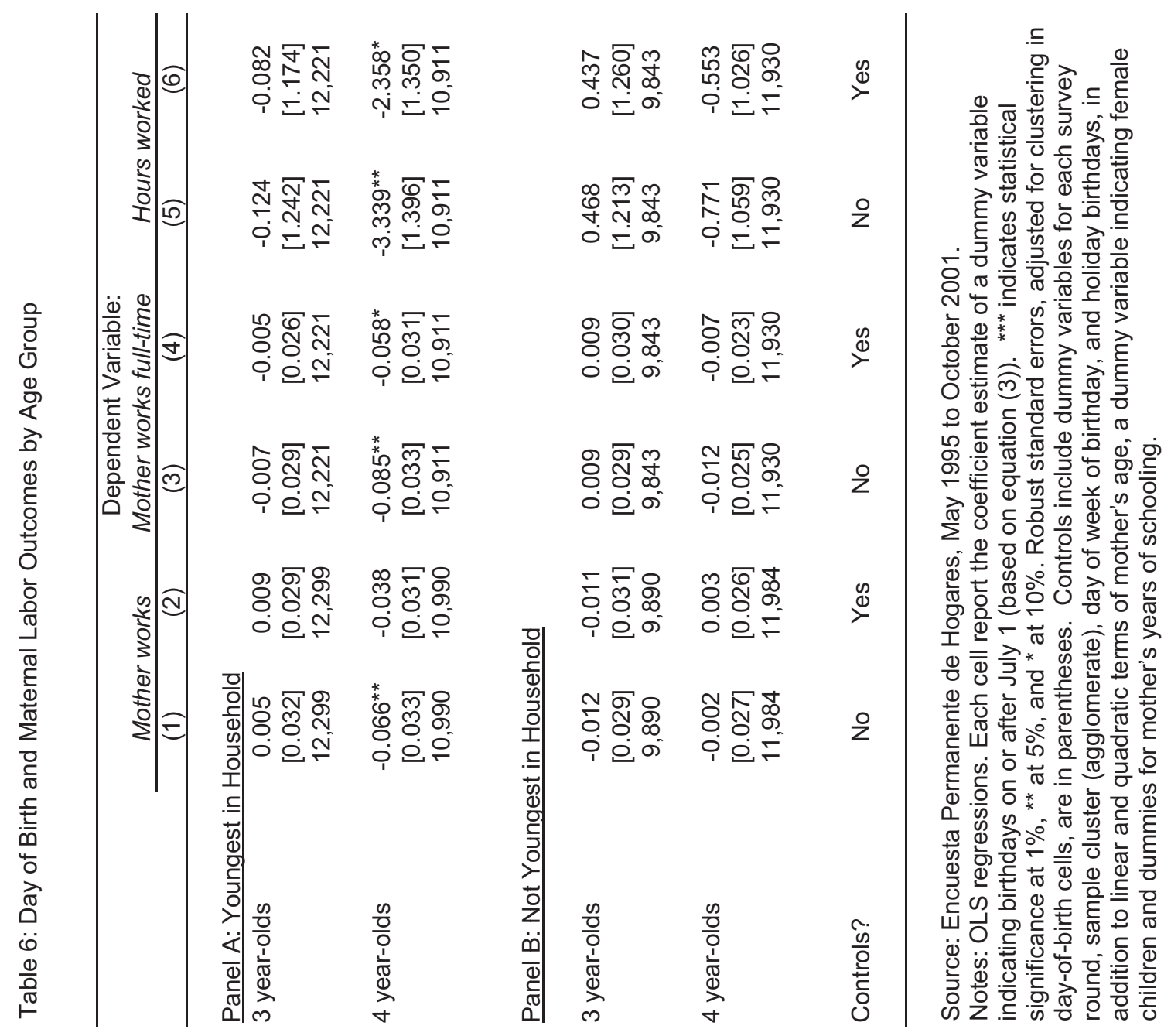




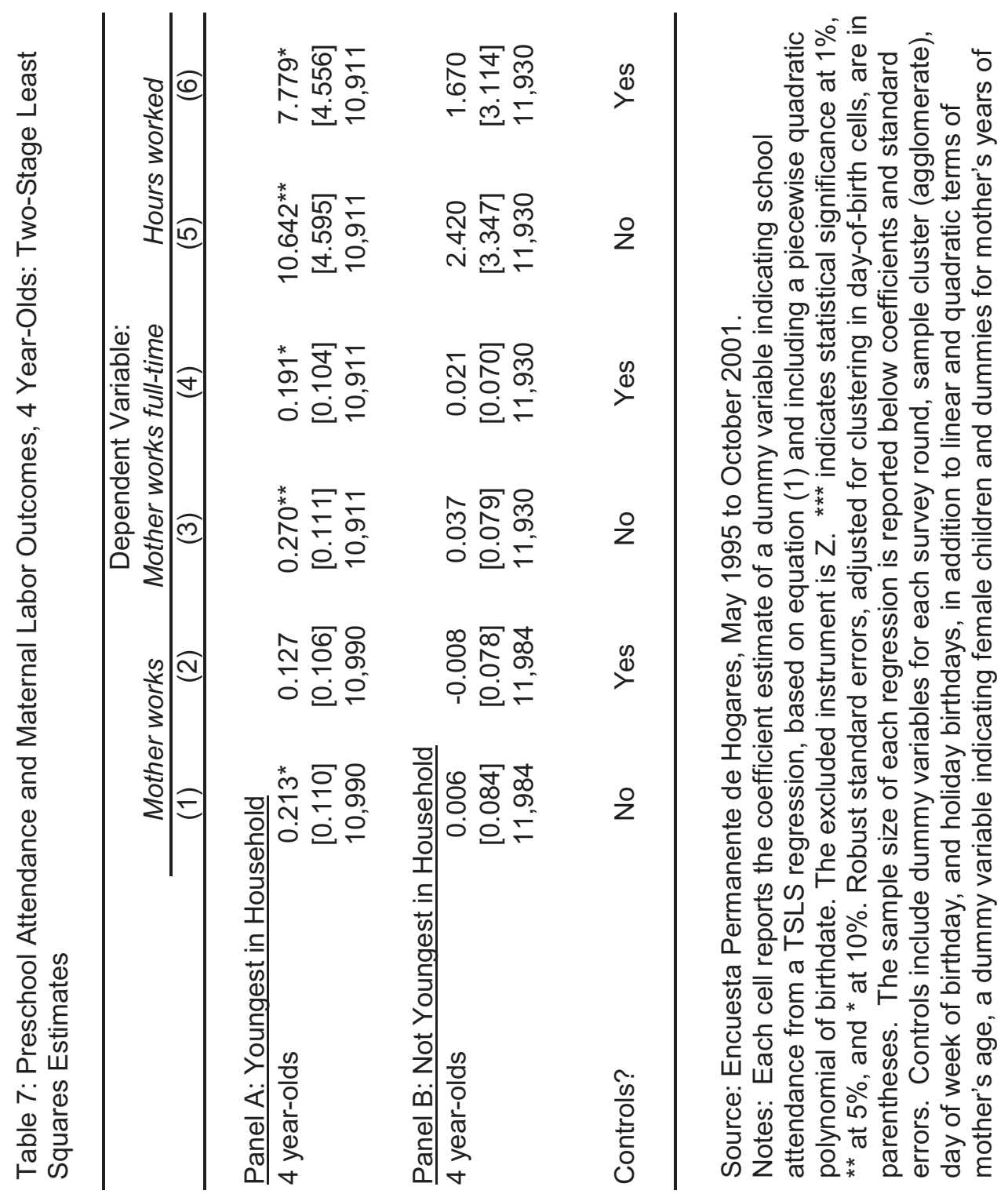




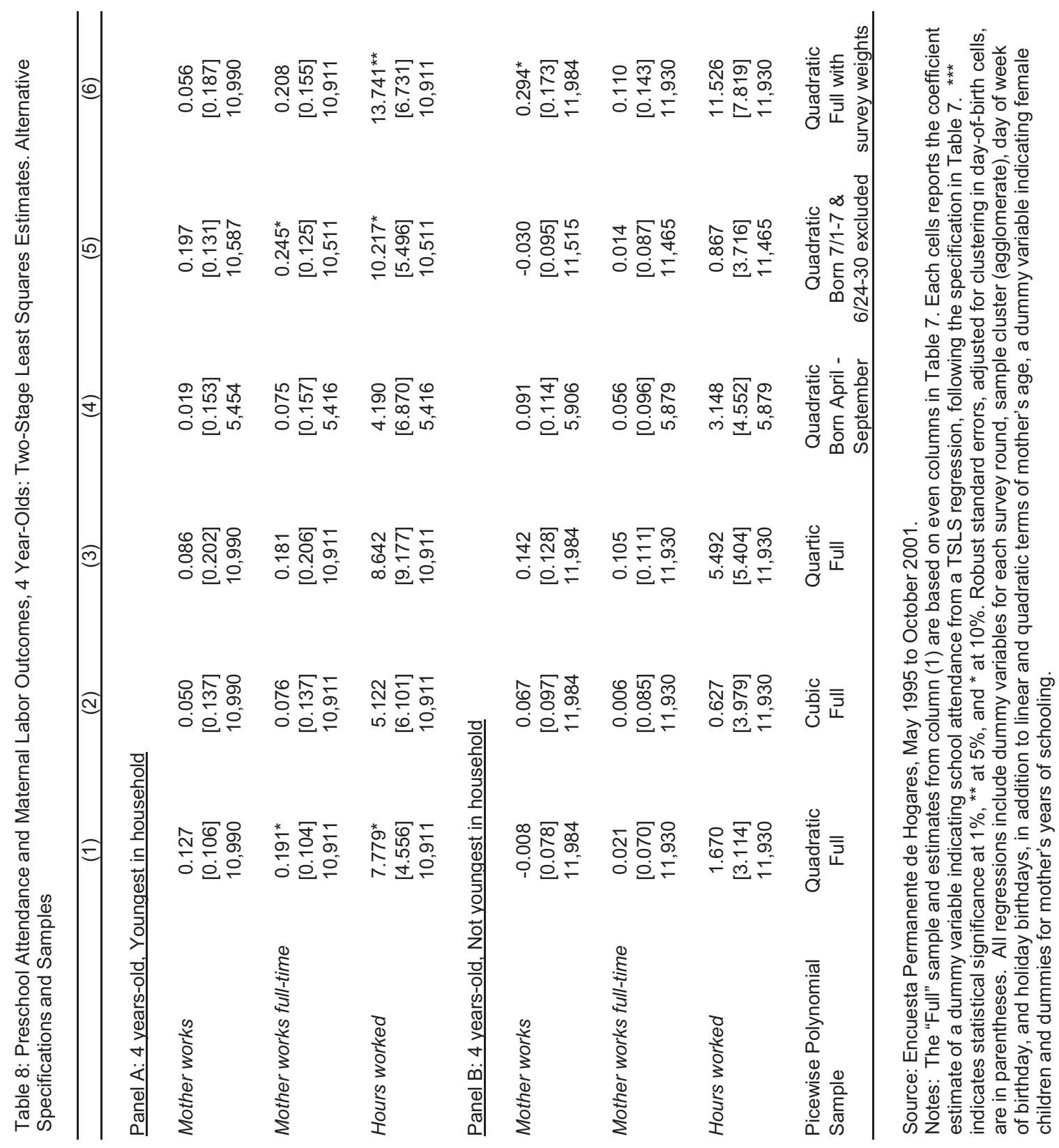




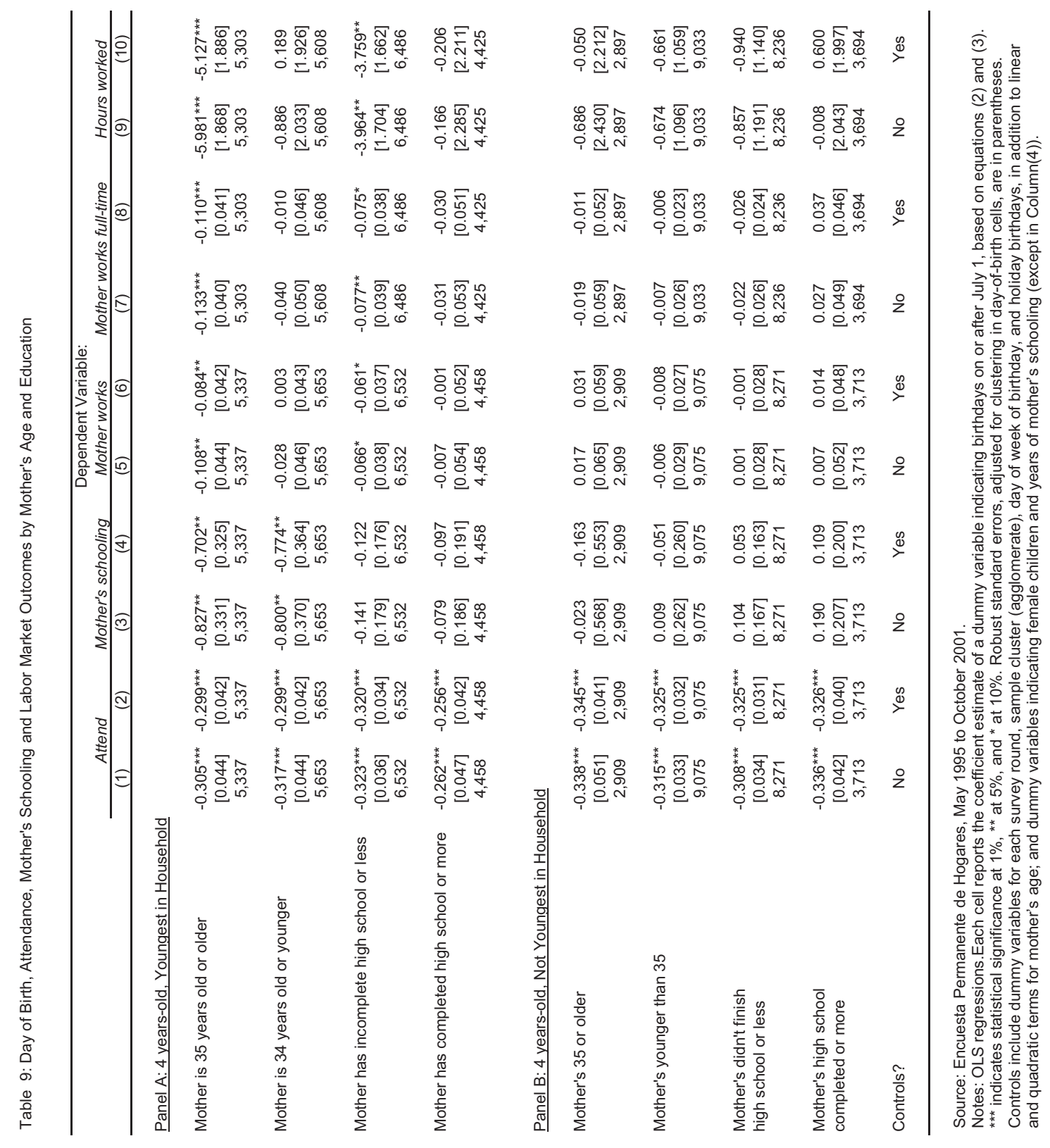




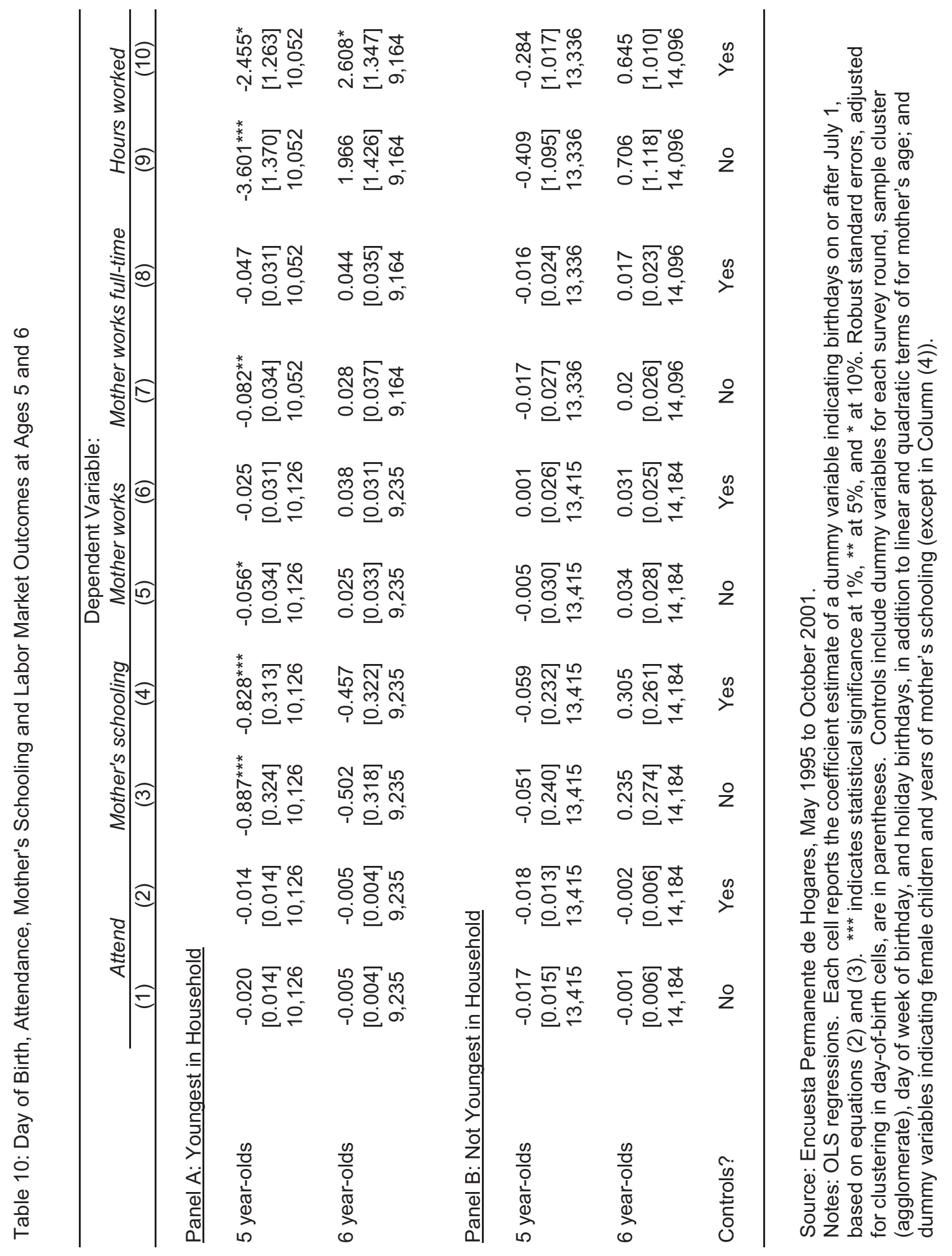



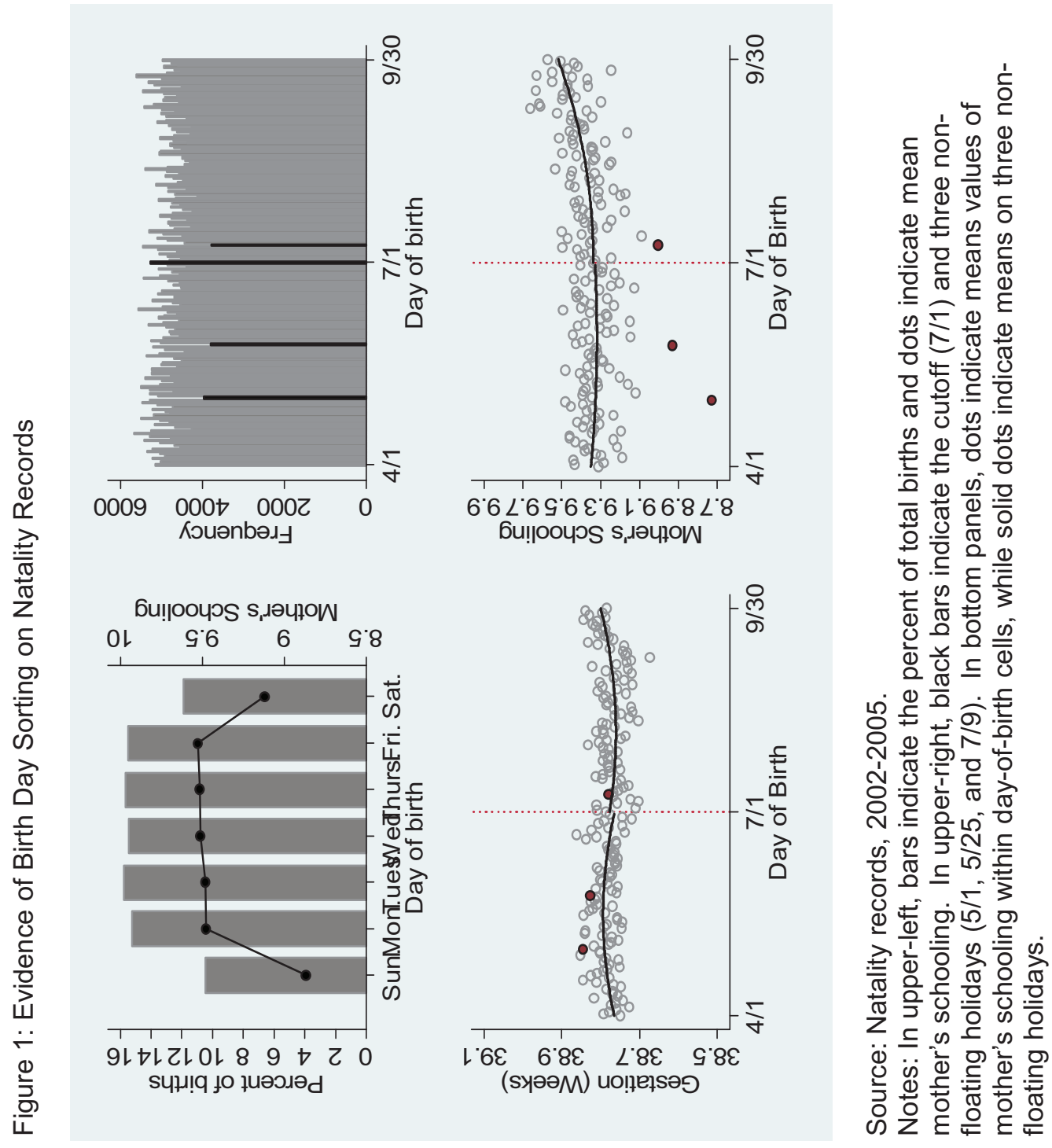


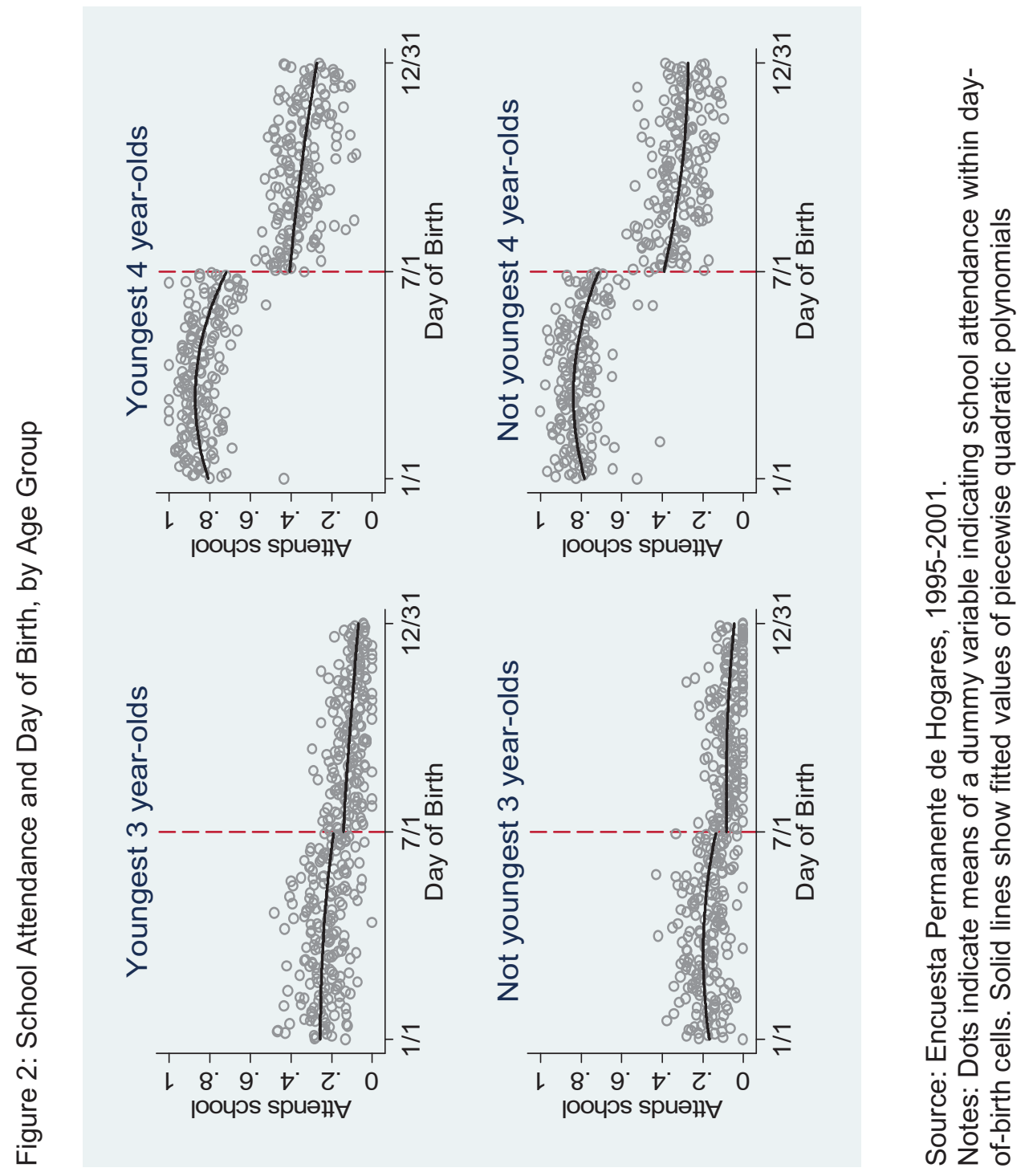




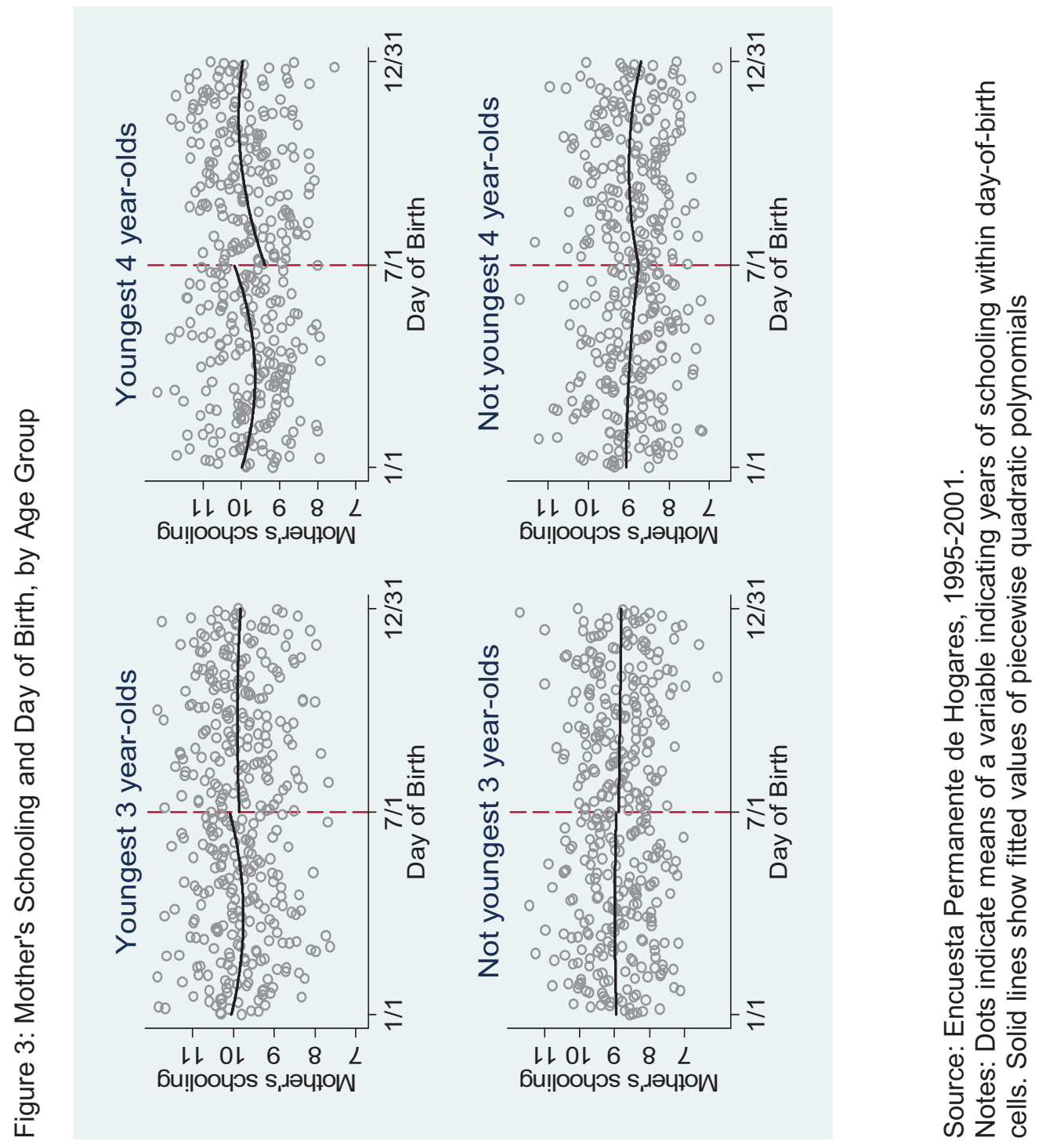




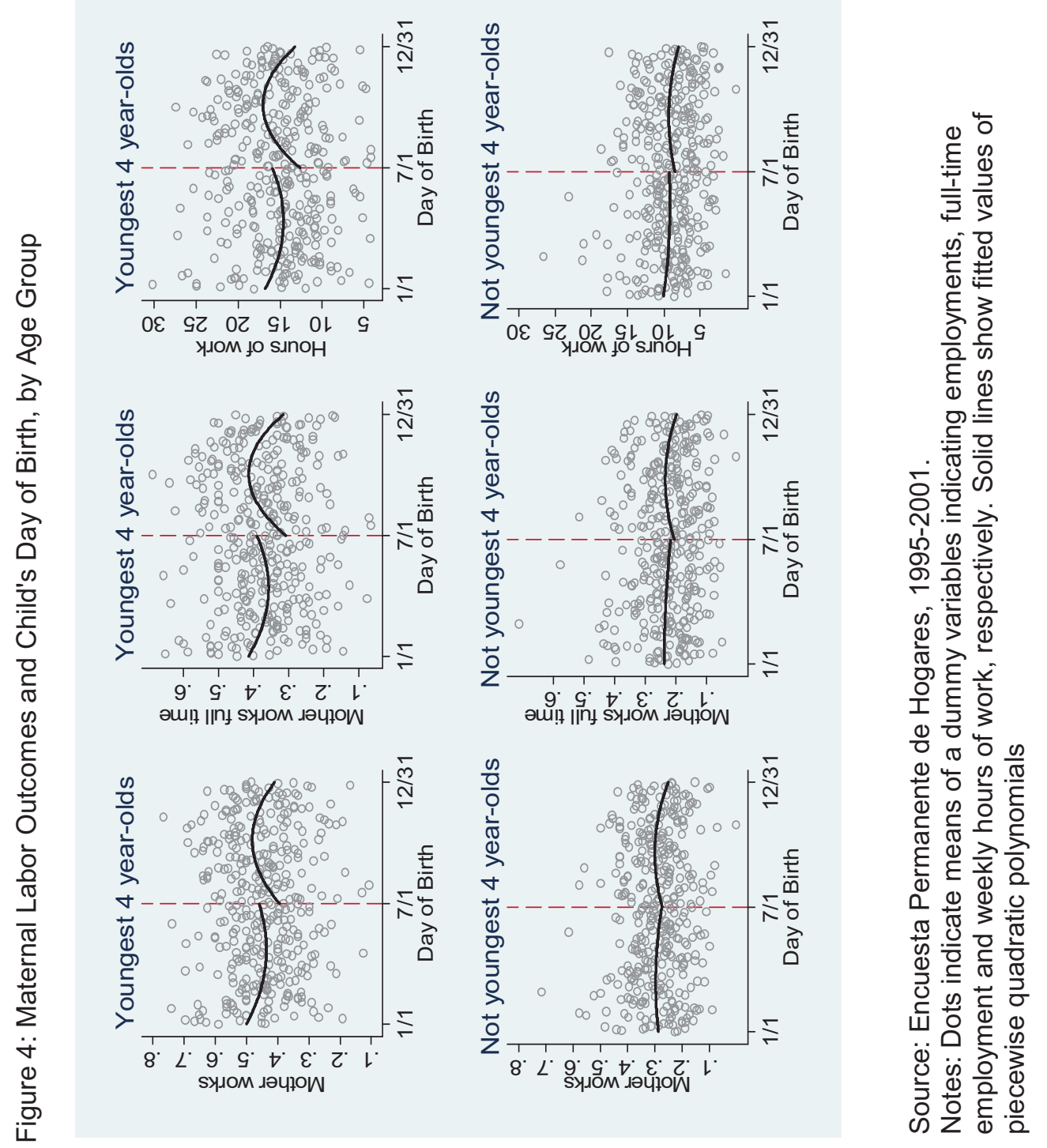

